\title{
BILATERAL AND SYNCHRONIC SEMINOMATOUS TESTICULAR NEOPLASIA
}

\author{
ADEMAR SCHMITZ \\ Maicé Hospital, Caçador, Santa Catarina, Brazil
}

\begin{abstract}
Testicular neoplasia is rare, especially when it is bilateral, and even more when it is synchronic, with its incidence being only $0.17 \%$ of germinative tumors of testicles.

We present here the case of a male, 32-year old patient, without children. Patient underwent a bilateral radical orchiectomy, following previous sperm harvest, in a sperm bank. Surgery was performed in 2 stages, with a 12-day interval, with implantation of a silicone testicular prosthesis. The result of anatomicopathological examination revealed bilateral classical seminoma, pT2 on the right side andT1 on the left. He was submitted to bilateral complementary radiotherapy, with 2,500 cGy on each side.

Patient had a good outcome from a medical and oncologic perspective, but a follow-up with psychotherapy was needed.
\end{abstract}

Key words: testis; testicular neoplasms; seminoma; synchronous neoplasms

Int Braz J Urol. 2003; 29: 330-1

\section{INTRODUCTION}

The incidence of germinative testicular tumors in the general population is $0.005 \%$, and accounts for $1 \%$ of all tumors that affect men. The risk of a patient having a successive (metachronic) bilateral tumor ranges between 1 and 5\% (1). As for synchronic tumors, they are even more rare. Recently a report was described on 2,431 germinative testicular tumors diagnosed and treated from 1978 to 1999 , and only 24 of these cases were bilateral, and among them 20 were metachronic, that is, $1 \%$ of all tumors. Synchronic tumors were described in only 4 cases $(0.17 \%)(2)$. The histological type is usually the same in both testicles, however in metachronic ones, histological types can be different.

Synchronous testicular tumors require a bilateral surgical therapy, leading to the patient's sterility.

\section{CASE REPORT}

Male, 32-year old patient, married with no children. He had 5-month history of bilateral, hard- ened, slightly painful, testicular mass, involving practically the entire glands. Ultra-sonography revealed a right testicle measuring $7.8 \times 8.4 \times 4.2 \mathrm{~cm}$ and left testicle measuring $5.4 \times 4.0 \times 2.7 \mathrm{~cm}$. The main hypothesis was bilateral neoplasia, without excluding a granulomatous process. Tumoral markers were normal. Thorax radiography and abdominal computerized tomography did not reveal metastases. The magnetic resonance imaging of scrotum suggested bilateral testicular neoplasia.

Surgery was indicated following adequate sperm harvests, in sperm banks, for subsequent use. Surgery was scheduled in 2 stages, for reasons of patient safety. The right radical orchiectomy, with previous approach of the spermatic cord, was followed by a silicone testicular implant. The anatomicopathological result was classical seminoma (Boden I-B stage or pT2N0M0), with focal invasion of the tunica albuginea, transposing it and the "rete testis" (Figure-1). The same procedure was performed on the left side, 12 days later, already with a definitive diagnosis. There was only a lymph node measuring $0.5 \mathrm{~cm}$ in the spermatic 


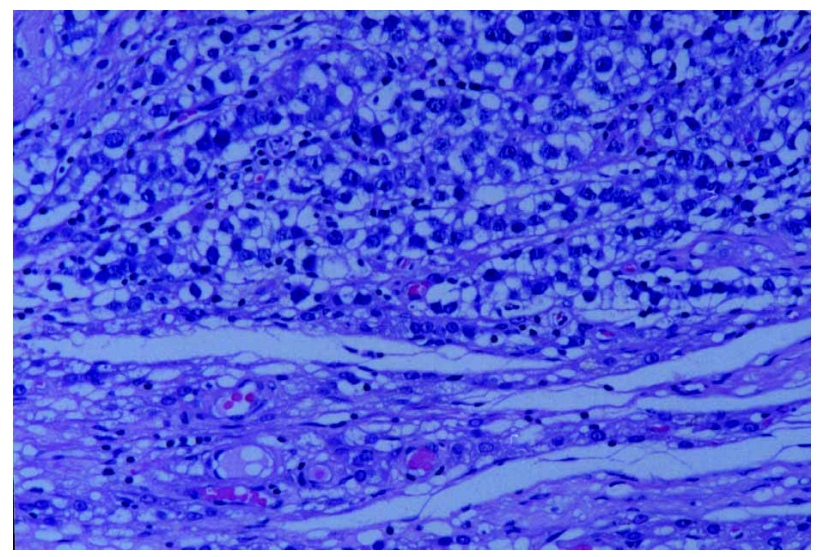

Figure 1 - Photomicrography of right testicle tumor, showing classical seminoma with invasion of the "rete testis" (HE, X2O0).

cord (Figure-2). The anatomicopathological diagnosis was seminoma as well (I-A stage or pT1NOM0), with focal invasion of the tunica albuginea, without transposing the capsule. The lymph node was negative for neoplasia.

As a complementary treatment, the patient was submitted to a conformational radiotherapy, with $2.500 \mathrm{cGy}$ at each side (bilateral iliac and para-aortic chains), 60 days after surgery. He presented a good outcome, and is receiving hormone replacement.

\section{DISCUSSION}

Bilateral germinative testicular tumors are rare and, when diagnosed synchronically, they are even rarer. Seminoma is the most common histological type. Current indication for treating such tumors begins with the clinical staging, with orchiectomy being the first step (3). It is hard to evaluate whether a conservative surgery, in bilateral cases,

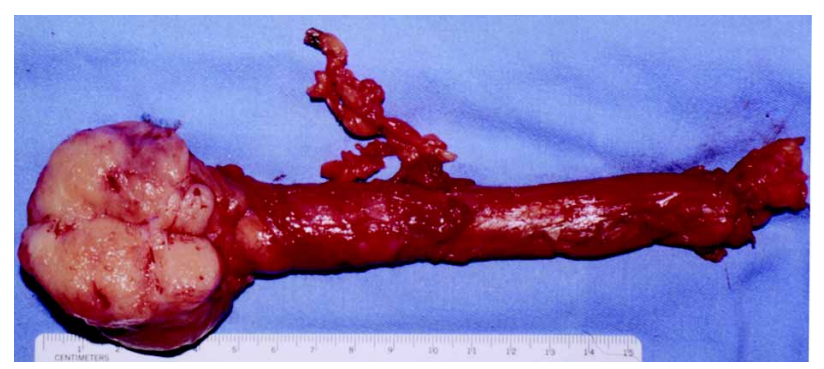

Figure 2-Surgical specimen of left side. Note the minimal thickness of normal tissue in the testicle periphery. followed by chemotherapy and/or radiotherapy, could provide good results without bilateral testicular ablation, due mainly to the reduced number of cases of studied synchronic tumors. In this particular case, such procedure could not have been possible, since both testicles were involved by the neoplasia, in more than $90 \%$ of the normal tissue, with only a small band of tubules with normal aspect (Figure-2). In this case there was a great resistance from patient and his wife, in accepting the bilateral surgical treatment, with a freeze biopsy only, choosing thus to perform a surgery in 2 times, even though we had the clinical diagnosis of neoplasia pre-operatively. Complementary treatment was radiotherapy, due to staging and bilaterality.

\author{
$\overline{\text { Figure-1 was supplied by Drs. Maria }}$ \\ CN Zerbini and Claudia RGCM Oliveira, \\ from Fleury Laboatory, SP
}

\section{REFERENCES}

1. Yokomizo S, Tsujimura A, Nonomura N, Kirime S, Takahara S, Okuyama A: Metachronous bilateral testicular tumors in a child. J Urol. 2001; 166: 2341.

2. Che M, Tamboli P, Ro JY, Park DS, Ro JS, Amato RJ, et al.: Bilateral testicular germ cell tumors: twenty-year experience at M.D. Anderson Cancer Center. Cancer 2002; 95: 1288-33.

3. Richie JP: Neoplasms of the Testis. In: Walsh PC, Retik AB, Vaughan ED Jr, Wein AJ (eds.), Campbell's Urology, $7^{\text {th }}$ ed. New York, WB Saunders. 1998; pp. 241152.

Received: February 28, 2003

Accepted after revision: May 9, 2003 